\section{THU0677 OUTCOME MEASUREMENT INSTRUMENTS FOR SAFETY IN RHEUMATOLOGY: A SCOPING REVIEW OF AVAILABLE INSTRUMENTS TO INFORM THE OMERACT SAFETY WORKING GROUP}

L. Klokker ${ }^{1}$, T. Woodworth ${ }^{2}$, D.E. Furst ${ }^{2}$, P. Tugwell ${ }^{3}$, D. Devoe ${ }^{4}$ P. Williamson ${ }^{5}$, C.B. Terwee ${ }^{6}$, M.E. Suarez-Almazor ${ }^{7}$, V. Strand ${ }^{8}$, A.L. Leong ${ }^{9}$, N. Goel ${ }^{10}$, M. Boers ${ }^{11}$, P.M. Brooks ${ }^{12}$, L.S. Simon ${ }^{13}$, R. Christensen ${ }^{1}$ on behalf of OMERACT working group. ${ }^{1}$ The Parker Institute, Bispebjerg \& Frederiksberg Hospital, Copenhagen, Denmark; ${ }^{2}$ David Geffen School of Med., Division Rheumatology, UCLA, Los Angeles, United States; ${ }^{3}$ Dept of Medicine, School of Epidemiology, Public Health and Community Medicine, University of Ottawa, Ottawa; ${ }^{4}$ Department of Medicine, University of Calgary, Cumming School of Medicine, Calgary, Canada; ${ }^{5}$ Institute of translational medicine, University of Liverpool, Liverpool, United Kingdom; ${ }^{6}$ Department of Epidemiology and Biostatistics, the EMGO Institute for Health and Care Research, VU University Medical Center, Amsterdam, Netherlands: ${ }^{7}$ Section of Rheumatology and Clinical Immunology, University of Texas MD Anderson Cancer Center, Houston; ${ }^{8}$ Div Imm/Rheum, Sanford University, San Fransisco; ${ }^{9}$ Healthy Motivation, Global Alliance for Musculoskeletal Health, Bone and Joint Decade, Santa Barbara;

${ }^{10}$ Advisory Services, Strategic Drug Development, Quintiles IMS, Morrisville NC, United States; ${ }^{11}$ Department of Epidemiology and Biostatistics, Amsterdam Rheumatology and immunology Center, VU University Medical Center, Amsterdam, Netherlands; ${ }^{12}$ Centre for Health Policy Melbourne School of Population, Global Health University of Melbourne, Melbourne, Australia; ${ }^{13}$ SDG LLC Cambridge, Cambridge MA, United States

Background: International scientific networks have raised concerns about inadequate reporting of safety outcomes in randomised trials and systematic reviews. Outcome Measures in Rheumatology (OMERACT) has previously developed an adaptation of the US National Cancer Institute (US NCI) Common Terminology Criteria for Adverse Events (CTCAE), the RCTC (Rheumatology Common Toxicity Criteria) to collect adverse events in rheumatology clinical trials. To respond to the need to also report safety outcomes from the patient perspective, the Safety Working Group is developing a core outcome set, followed by a core outcome measurement set. A scoping review of available instruments for measuring safety outcomes is needed to inform this work.

Objectives: To identify candidate measurement instruments for safety outcomes in rheumatology clinical trials.

Methods: A systematic search was performed in the MEDLINE database (via PubMed) in January 2017 using MeSH terms covering synonyms for adverse events, rheumatology and measurement instruments and the Boolean operator AND to combine them. Full-text articles about the development or evaluation of instruments for measuring safety in rheumatology were eligible. One reviewer (LK) screened for eligibility based on title and abstracts. Two reviewers (LK and RC) screened the full text articles.

Results: Of 434 unique references identified, 19 were read in full-text, and 8 were included (see figure). The instruments identified were: Glucocorticoid Toxicity Index (GTI), Patient Reported Experiences and Outcomes of Safety in Primary Care (PREOS-PC), Safety of Estrogens in Lupus Erythematosus National Assessment (SELENA)-SLEDAl flare index (CSFI), the BioSecure questionnaire, Rheumatology Common Toxicity Criteria (RCTC), OMERACT $3 \times 3$, and the Stanford Toxicity Index (STI). These instruments were specific for substance
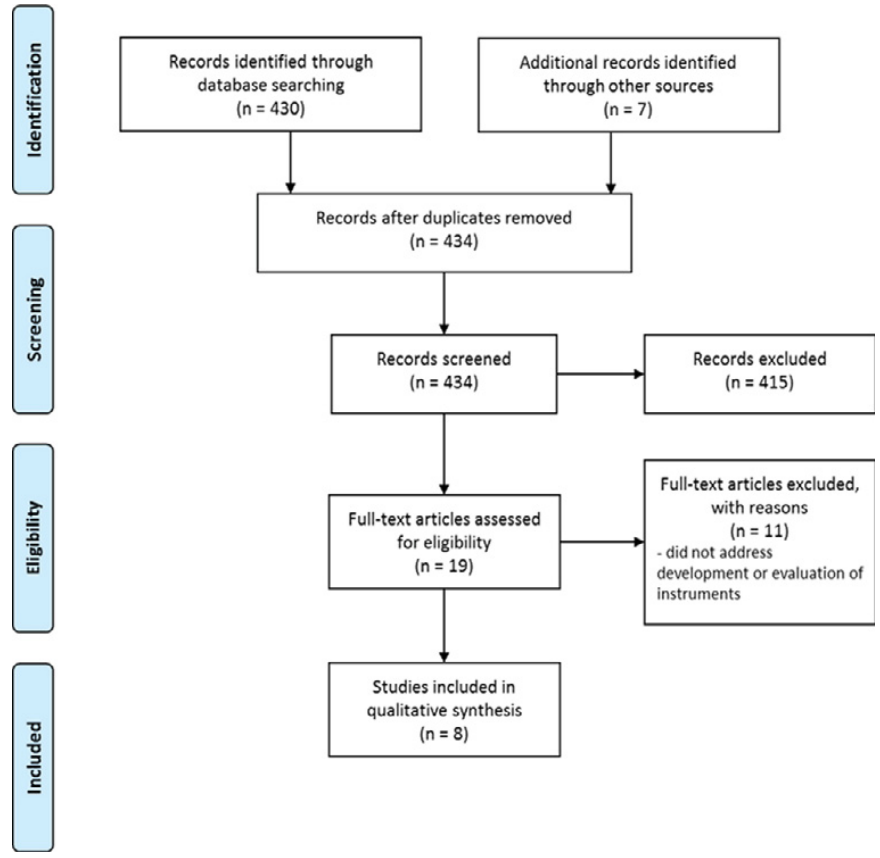

Figure 1
(GTI, BioSecure questionnaire), setting (PREOS-PC), condition (cSFI), or not fully validated (RCTC, OMERACT $3 \times 3$, STI).

Conclusions: The instruments identified are either too specific, or require further development/evaluation, for the purpose of standardizing measurement of safety in rheumatology clinical trials. Thus, we will proceed to gain consensus on the domains that must be measured to develop a core outcome set.

Disclosure of Interest: None declared

DOI: 10.1136/annrheumdis-2017-eular.6141

\section{THU0678 EXPRESSION OF ADHESION MOLECULES CD44V3 AND CD44V6 ON T CELLS IN SLE PATIENTS: CORRELATION WITH CLINICAL PHENOTYPE AND DISEASE ACTIVITY}

L. Novelli ${ }^{1}$, C. Barbati ${ }^{1}$, F. Ceccarelli ${ }^{1}$, C. Perricone ${ }^{1}$, F.R. Spinelli ${ }^{1}$,

C. Alessandri ${ }^{1}$, G. Valesini ${ }^{1}$, R. Perricone ${ }^{2}$, F. Conti ${ }^{1} .{ }^{1}$ Lupus Clinic, Sapienza University of Rome, Italy; ${ }^{2}$ Rheumatology, Allergology and Clinical Immunology, Tor Vergata University, Rome, Italy

Background: Adhesion molecule CD44 enables T lymphocytes' adhesion to endothelium. During inflammation, increased expression of CD44 contributes to T cell migration into target organs. Infiltration of peripheral tissues is crucial in the development of SLE organ damage and the different isoforms of CD44 seem to be involved in this process. Both CD44v3 and CD44v6 isoforms have been found in kidney biopsies of SLE patients, and CD44v3 in the skin only ${ }^{1,2}$. A higher expression of CD44v3 and $v 6$ has been identified on T cells from SLE patients compared to healthy subjects (HS) and the expression levels seem to correlate with disease activity ${ }^{3}$.

Objectives: The aim of this study was to investigate the expression of the CD44v3/v6 isoforms on T cells of SLE patients and their correlation with disease activity and clinical phenotype.

Methods: We enrolled 23 patients $(23 F$, mean age \pm SD $45.7 \pm 13$ years, mean disease duration \pm SD $13 \pm 8$ years) affected by SLE according to the 1997 ACR criteria, and $14 \mathrm{HS}(14 \mathrm{~F}$, mean age \pm SD $34.28 \pm 12.7$ years). Disease activity was measured by SLEDAI-2K. 10 patients were in remission (SLEDAI-2K=0) and 13 patients had an active disease (SLEDAI-2K $\geq 4$ ). Expression of CD44v3 and $v 6$ on T cells was determined by flow cytometry analysis.

Results: Expression of CD44v3 and v6 was significantly higher in active and remission patients compared to HS on CD4+ and CD8+ T cells. SLE patients with active disease showed a trend of major expression of CD44v3 and $v 6$ on $\mathrm{CD} 4+$ and $\mathrm{CD} 8+$ cells compared to patients in remission (Fig.1). CD44v3/CD44v6 expression ratio on CD4+ and CD8+ T cells was shifted towards isoform v3 on CD4+ cells and towards isoform v6 on CD8+ cells in SLE patients in remission and HS. In active disease this ratio was shifted towards isoform v6 on both T cells populations (Table 1). By using a ROC curve analysis, CD44v6 on CD4+ T cells resulted the most sensitive and specific one (sensitivity $82.6 \%$, specificity $78.6 \%$ ). Finally, we observed a significant correlation between CD44v3 on CD4+ cells and skin involvement $(P=0.027, r=0.632)$.

\begin{tabular}{lcc}
\hline Ratio & CD4 CD44v3/CD4 CD44v6 & CD8 CD44v3/CD8 CD44v6 \\
\hline Healthy subjects & 1.14 & 0.74 \\
SLE SLEDAl-2k=0 & 1.58 & 0.82 \\
SLE SLEDAl-2k $\geq 4$ & 0.82 & 0.67
\end{tabular}

CD44V3 $\mathrm{CD} 4+\quad 0.82$
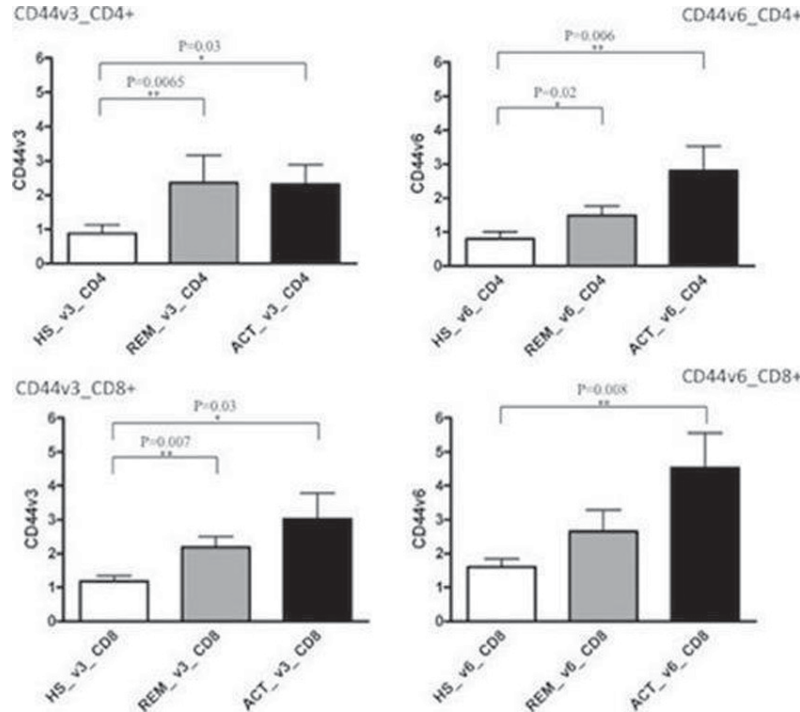

Conclusions: Our study confirms previous evidences suggesting a higher expression of CD44v3 and v6 on T cells from SLE patients compared to HS. Higher expression of CD44v3 and v6 on patients with active disease suggests their possible use as biomarkers of disease activity. The good specificity and sensitivity of CD44v6 on CD4+ T cells, and the shift of the ratio towards this 
isoform in active patients, suggest a stronger value of this isoform as a biomarker of disease activity.

References:

[1] Cohen RA, Bayliss G, Crispín JC et al. T cells and in situ cryoglobulin deposition in the pathogenesis of lupus nephritis. Clin Immunol 2008;128:1-7.

[2] Seiter S, Schadendorf D, Tilgen et al. CD44 variant isoform expression in a variety of skin-associated autoimmune diseases. Clin Immunol Immunopathol 1998;89:79-93.

[3] Crispín JC, Keenan BT, Finnell MD et al. Expression of CD44 variant isoforms CD44v3 and CD44v6 is increased on T cells from patients with systemic lupus erythematosus and is correlated with disease activity. Arthritis Rheum 2010;62:1431-7.

Disclosure of Interest: None declared

DOI: 10.1136/annrheumdis-2017-eular.3671

\section{THU0679 CAN THE USE OF NEW TECHNOLOGIES IMPROVE THE USE OF PATIENT REPORTED OUTCOMES (PROS) AND PATIENT PARTICIPATION IN A NATIONAL REGISTRY?}

L. Cunha-Miranda ${ }^{1}$, H. Santos ${ }^{1}$, F. Barcelos ${ }^{1}$, N. Madeira ${ }^{1}$, S. Fernandes ${ }^{1}$ J. Borges $^{1}$, R. Marques ${ }^{1}$, C. Silva ${ }^{1}$, C. Miguel $^{1}$, A. Cardoso $^{2}$, R. Trinca ${ }^{3}$, A. Faustino ${ }^{1}$. ${ }^{1}$ Rheumatology; ${ }^{2}$ Nutrition; ${ }^{3}$ Nurse Day Hospital, Instituto Português de Reumatologia, Lisboa, Portugal

Background: PROs are especially useful in the management of rheumatic diseases in complement to physician evaluation. However they are time consuming and used in a limited manner in the daily clinical practice.

Reuma.pt is the Portuguese national rheumatic diseases register and one of the few registries in Europe that allows the patient to do at home the PROs before the appointment. In our institute we have complemented that with the creation of a paper free day hospital with the use of touch screen computers that also allows the patient to do the PROs before the clinical evaluation by the rheumatologist.

Objectives: to compare the impact of the use off Reuma.pt at home PROs completion platform before and after the utilization of touch screen computers in the day hospital.

Methods: We determined the number of patients and appointments with the use at home of the PROs platform one year prior to the introduction of the touch screen computer at our day hospital (October 2014 -October 2015) and one year after the paper free day hospital was installed (November 2015-November 2016). To determine any change of pattern of the use at home of the platform and the relations between that and patients characteristics.

Results:

Table 1. Diferences between previous use of touchscreen computers in the use at home PROs

\begin{tabular}{lcc}
\hline & $\begin{array}{c}\text { T0 } \\
\text { October 2014 to } \\
\text { October 2015 }\end{array}$ & $\begin{array}{c}\text { T1 } \\
\text { November 2015 to } \\
\text { November de 2016 }\end{array}$ \\
\hline $\begin{array}{c}\text { Number of appointments with PROs done at } \\
\quad \text { home/total of appointments with }\end{array}$ & & \\
$\quad$ completed PROs/percentage & $93 / 419 / 22.1 \%$ & $216 / 448 / 48,2 \%$ \\
Number of patients with PROs done at home & 57 & 106 \\
Age & $45.19 \pm 10.33$ & $49.82 \pm 11.54$ \\
Sex & $40 \mathrm{~F}+17 \mathrm{M}$ & $75 \mathrm{~F}+31 \mathrm{M}$ \\
Mean school years & $11.79 \pm 3.96(\mathrm{~N}=29)$ & $10.35 \pm 4.3(\mathrm{~N}=68)$ \\
Under biologics & 53 appointments (56.99\%) & 162 appointments $(75 \%)$ \\
Diagnosis & 43 AS, 11 RA e 3 PsA & $61 \mathrm{AS}, 33 \mathrm{RA}$ e 12 PsA \\
\hline
\end{tabular}

When we analyse the available variables between the patients that performed the PROs at home we found for both periods considered that they were younger $(45,2 / 49,8$ vs $53,4 / 55,1 p<0.001)$ they have more education $(11.8 / 10.35$ vs $8.2 /$ $7,9)$ no differences were found regarding gender. There is a tendency that with the continuous use of touchscreen computers at the day hospital less educated (T0 -11.8, T1-10.35 school years) and older patients (T0- 45,2/ T1 -49,8 years) are using more at home platform of Reuma.pt.

Conclusions: The use of technology could have a consider impact on the way we collected data from our patients. With the use of a touchscreen computer we have improved not only the overall completion of PROs but also increased the familiarity of patient to the online questionnaires. Number of appoitments with previous at home completion of the questionnaires more than double. This has a clear impact on patient participation, quality of data in the registry but even more impact on time and human resources at a day hospital.

Disclosure of Interest: None declared

DOI: 10.1136/annrheumdis-2017-eular.7001

\section{THU0680 VALIDATION OF EQ-5D, RAPID-3 AND HADS QUESTIONNAIRES FOR THE ASSESSMENT OF THERAPY EFFICACY IN PANNICULITIS PATIENTS}

N. Savushkina, V. Amirdjanova, O. Egorova, B. Belov. V. A. Nasonova Research Institute of Rheumatology, Moscow, Russian Federation

Background: $\mathrm{Pn}$ is a group of heterogeneous inflammatory diseases characterized by involvement of the subcutaneous fat (SF), locomotor system and viscera, and the number of panniculitis $(\mathrm{Pn})$ cases is increasing in everyday practice of a rheumatologists. There are no specific scales available to assess efficacy of Pn therapy. EQ-5D, RAPID-3 and HADS validity, sensitivity and specificity were proven for some rheumatic diseases. Thus, evaluation of EQ-5D, RAPID-3 and HADS psychometric properties in Pn patients has become the objective of this study.

Objectives: Evaluate psychometric properties of questionnaires EQ-5D, RAPID-3 and HADS in Pn patients.

Methods: The study group included $83 \mathrm{Pn}$ pts (80 females, 3males) aged $43,4 \pm 13,9$ years with median disease duration of $5[2 ; 24]$ months who were at the record of V. A. Nasonova Research Institute of Rheumatology during 2009-2015 yy. All patients filled in EQ-5D, RAPID-3 and HADS questionnaires during the first and the control visits at 12 months. Questionnaires' sensitivity was assessed by comparing patient's answers and objective response to therapy measured by achievement of complete regression of the nodules on the control visit. The construct validity was measured based on correlation with "external criteria", including presence of arthritis and arthralgias, tenderness of nodules at palpation measured by VAS, ESR and CRP values.

Results: Positive dynamics (nodule regression) correlated with improved EQ-5D (EQ-5D-scale - $p=0,005$, EQ-5D-VAS - $p=0,004)$ and RAPID-3 $(p=0,0011)$. Median $\triangle \mathrm{EQ}-5 \mathrm{D}$ and HADS-depression after therapy were $0,27[0,12 ; 0,45](p=0,005)$, and $2[1 ; 5](p=0,13)$ scores, respectively, while average decline in RAPID-3 and HADS-anxiety scores after therapy was 9,2 $\pm 5,2(p=0,0011)$ and $4 \pm 3(p=0,15)$, respectively. EQ-5D showed the greatest power in Pn patients' quality of life assessment. EQ-5D-scale and VAS-"thermometer" showed moderate correlation with nodule tenderness at baseline $(r=-0,23, p=0,036) \&(r=-0,45, p=0,0003)$, and control visits (12 months) ( $r=-0,38, p=0,0002)$ \& $(r=-0,41, p=0,0002)$; EQ-5D-scale showed moderate correlation with ESR and CRP values at the control visit $(r=-0,23, p=0,03) \&(r=-0,25, p=0,005)$, and EQ-VAS - with CRP value at 12 months $(r=-0,33, p=0,002)$, demonstrating clear correlation with patient's objective health status and lab parameters values. Moderate correlation between functional RAPID-3 values and nodule tenderness at baseline $(r=0,34$, $p=0,0015)$ and after 12 months $(r=0,5, p<0,0001)$ are also indicative of close links between the questionnaire data and pts' objective health status. As for the HADS scale, moderate correlation was found only between HADS-depression and nodule tenderness at baseline $(r=-0,24, p=0,026)$ and 12 months $(r=0,28$, $p=0,014)$ visits. There were no other significant correlations identified.

Conclusions: EQ-5D and RAPID-3 questionnaires should be considered as valid and sensitive instruments for the assessment of the quality of life and efficacy of therapy in Pn pts.

Disclosure of Interest: None declared

DOI: 10.1136/annrheumdis-2017-eular.2518

\section{THU0681 BASELINE ESSDAI/DAS SCORES IN 8061 PATIENTS WITH PRIMARY SJÖGREN SYNDROME: CHARACTERIZATION OF SYSTEMIC DISEASE}

P. Brito-Zerón ${ }^{1,2}$, N. Acar-Denizli ${ }^{3}$, M. Zeher ${ }^{4}$, A. Rasmussen ${ }^{5}$, X. Li ${ }^{6}$, C. Baldini ${ }^{7}$, J.-E. Gottenberg ${ }^{8}$, D. Danda ${ }^{9}$, L. Quartuccio ${ }^{10}$,

G. Hernandez-Molina ${ }^{11}$, A.A. Kruize ${ }^{12}$, S.-H. Park ${ }^{13}$, M. Kvarnström ${ }^{14}$, S. Praprotnik ${ }^{15}$, D. Sene ${ }^{16}$, A. Alunno ${ }^{17}$, R. Solans ${ }^{18}$, T. Mandl $^{19}$, Y. Suzuki $^{20}$, M. Rischmueller ${ }^{21}$, G. Nordmark ${ }^{22}$, G. Fraile ${ }^{23}$, P. Wiland ${ }^{24}$, H. Bootsma ${ }^{25}$ T. Nakamura ${ }^{26}$, V. Valim ${ }^{27}$, R. Giacomelli ${ }^{28}$, R. Seror ${ }^{29}$

V. Devauchelle-Pensec ${ }^{30}$, B. Hofauer ${ }^{31}$, M. Bombardieri ${ }^{32}$, V. Trevisani ${ }^{33}$, D. Hammenfors ${ }^{34}$, A. Minniti ${ }^{35}$, S.G. Pasoto ${ }^{36}$, J. Morel $^{37}$, S. Retamozo ${ }^{38}$, T.A, Gheita ${ }^{39}$, F. Atzeni ${ }^{40}$, C. Vollenveider ${ }^{41}$, X. Mariette ${ }^{29}$, M. Ramos-Casals ${ }^{2}$ on behalf of EULAR-SS TF Big Data Consortium. ${ }^{1}$ Hosp CIMA-Sanitas; ${ }^{2}$ Hosp Clínic, Barcelona, Spain; ${ }^{3}$ Msgsü, Istanbul, Turkey; ${ }^{4}$ Univ, Debrecen, Hungary; ${ }^{5}$ OMRF, Oklahoma, United States; ${ }^{6}$ Anhui Hosp, Hefei, China; ${ }^{7}$ Univ, Pisa, Italy; ${ }^{8}$ Univ, Strasbourg, France; ${ }^{9} \mathrm{CMC}$, Vellore, India; ${ }^{10}$ Santa Maria, Udine, Italy; ${ }^{11}$ INCMNSZ, México, Mexico: ${ }^{12}$ UMC, Utrecht, Netherlands; ${ }^{13}$ Catholic Univ, Seoul, Korea, Republic Of; ${ }^{14}$ Karolinska Instit, Stockholm, Sweden; ${ }^{15} \mathrm{UMCL}$ Ljubljana, Slovenia; ${ }^{16}$ Lariboisière Hosp, Paris, France; ${ }^{17}$ Univ, Perugia, Italy; ${ }^{18}$ Hosp Vall Hebron, Barcelona, Spain; ${ }^{19}$ Lund Univ, Malmö, Sweden; ${ }^{20}$ Univ, Kanazawa, Japan; ${ }^{21}$ TQEH, Adelaide, Australia; ${ }^{22}$ Univ, Uppsala, Sweden; ${ }^{23}$ Hosp Ramón Cajal, Madrid, Spain; ${ }^{24}$ Med Hosp, Wroclaw, Poland: ${ }^{25}$ Univ, Groningen, Netherlands; ${ }^{26}$ Univ, Nagasaki, Japan; ${ }^{27}$ UFES, Vitória, Brazil; ${ }^{28}$ Univ, L'Aquila, Italy; ${ }^{29}$ Univ Sud, Paris; ${ }^{30}$ Univ, Brest, France; ${ }^{31}$ TUM, München, Germany; ${ }^{32}$ QMUL, London, United Kingdom; ${ }^{33}$ UNIFESP, Sao Paulo, Brazil; ${ }^{34}$ Haukeland Hosp, Bergen, Norway; ${ }^{35}$ Sapienza Univ, Rome, Italy; ${ }^{36}$ USP, Sao Paulo, Brazil; ${ }^{37}$ Univ, Montpellier, France; ${ }^{38}$ INICSA, Cordoba, Argentina; ${ }^{39}$ Univ, Cairo, Egypt; ${ }^{40}$ L.Sacco Univ, Milan, Italy; ${ }^{41}$ German Hosp, Buenos Aires, Argentina

Objectives: To characterize and quantify systemic involvement at diagnosis in a large international cohort of patients with primary Sjögren's syndrome (SS).

Methods: The Big Data Sjögren Project was formed in 2014 to take a "highdefinition" picture of primary SS at diagnosis by merging international databases (9302 consecutive patients from 21 countries of the 5 continents). The main features (including ESSDAI/DAS) at diagnosis were analysed.

Results: Baseline ESSDAI was available in 8061 patients $(93 \%$ female, mean age $53 \mathrm{yrs}$ ). The mean ESSDAI score at diagnosis of the entire cohort was $6.4 \pm 7.9$. In 1498 patients (19\%), score at diagnosis was 0, while $681(8 \%)$ presented with high activity in at least one domain. The main systemic features at diagnosis were 